This is the accepted (post-print) version of the following published article:

Picton, C., Kahu, E. R., \& Nelson, K. (2018). 'Hardworking, determined and happy': First-year students' understanding and experience of success. Higher Education Research \& Development, 37(6), 1260-1273. doi:10.1080/07294360.2018.1478803

\title{
Student engagement in the educational interface: Understanding the mechanisms of student success
}

\author{
Ella R. Kahu \& Karen Nelson
}

Student success and retention continue to be of concern for higher education institutions. Wider participation combined with lower completion rates for non-traditional students highlight the need for new ways of understanding the student experience to ground policy and practice. This article provides this insight by drawing together a number of key constructs to refine a recent framework of student engagement. We argue that the transition metaphor, focusing on the first year, is limited because it depicts differences between students and institutions as both transient and temporal. Instead we use a cultural lens to introduce the educational interface as a metaphor for the individual psychosocial space within which institutional and student factors combine and student engagement in learning occurs. Incorporating the interface into the existing framework of student engagement makes three contributions to our understanding of the student experience. First, the educational interface is a tangible way of representing the complex interactions between students and institutions, and how those interactions influence engagement. Second, the refined framework highlights four specific psychosocial constructs: self-efficacy, emotions, belonging, and well-being, which we contend are critical mechanisms for mediating the interactions between student and institutional characteristics and student engagement and success. Finally, the refined framework helps explain why some students with demographic characteristics associated with lower completion rates, are retained and do go on to successfully complete their studies, while similar others do not. These three contributions: the interface, the key constructs within it being mediating mechanisms, and their explanatory utility, provide focus for the design and implementation of curricula and co-curricular initiatives aimed at enhancing student success and retention, and importantly to evaluate the impact of these interventions.

Key words: student engagement, transition, student success 


\section{Introduction}

Student success, whether measured by grades, retention statistics, or qualification completion rates, continues to be a concern of governments, higher education policy makers, leaders, and practitioners. Low success rates are particularly concerning for under-represented groups of students, which in Australia include Indigenous students and those from lower socio-economic backgrounds (LSES), remote areas, and regional locations (Bradley, Noonan, Nugent, \& Scales, 2008). Arguments for attending to student retention and completion are varied and include social justice concerns that see higher education as breaking cycles of social and cultural inequity and disadvantage (Devlin, 2013; Gale, 2011), politicised concern over the rising costs of uncapped higher education, and debate over the balance between public and private investment and the return on that investment for individuals and funding bodies (Baum, Ma, \& Payea, 2013; Trow, 2006).

Student engagement is widely recognised as critical - simply put, students who are engaged with their studies are more likely to be successful. However, the mechanisms contributing to the individual student's engagement have not yet been clearly articulated and the term engagement is used differently in various contexts. We understand engagement as an individual student's psychosocial state: their behavioural, emotional, and cognitive connection to their learning (Fredricks, Blumenfeld, \& Paris, 2004). This paper extends Kahu's (2013) conceptual framework of student engagement. While the original framework acknowledges the influence of both student and institutional factors, it does not illuminate how those factors interact and impact on the underlying psychosocial mechanisms that influence individual student success. Therefore it did not provide specific focus for understanding how to design and implement curricula and co-curricular initiatives that can enhance student success and retention.

By drawing on transition theory and cultural studies, we propose that individual student engagement occurs dynamically within an educational interface at the intersection of the student and their characteristics and background, and the institution and its practices. We contend that the educational interface, when integrated into Kahu's (2013) earlier framework, offers a cogent explanation for the dynamic, complex, and individual nature of students' psychosocial learning experiences - and highlights mechanisms critical for engaging all students, and particularly nontraditional students. Finally, we outline four psychosocial constructs (the mechanisms) that help explain how students experience the educational interface and how that experience impacts on their engagement and therefore success and retention.

The refined framework's contribution to student engagement research is a tangible representation of how and where the interactions between institutional and student factors occur. It also offers a more comprehensive depiction of the psychosocial mechanisms that facilitate students' connections or disconnections to their study. By describing these mechanisms, the refined framework provides clarity for academic and professional practitioners about which mechanisms need to be 
activated by curricula and co-curricular initiatives to promote students' engagement in learning. While the scope of this paper is limited to the refinement of the framework, we are concurrently conducting a programme of qualitative research investigating how the mechanisms in the interface influence the engagement of a contemporary student cohort (see for example, Kahu, Nelson, \& Picton, 2017, and Picton, Kahu, \& Nelson, 2017).

\section{Student success}

Reviews of higher education (e.g. Behrendt, Larkin, Griew, \& Kelly, 2012; Bradley et al., 2008), economic demands for a more highly skilled workforce to enable competition in the global economy, as well as increasing evidence of the individual and societal benefits of higher education (Department for Business Innovation and Skills, 2013), all trigger concerns over student success rates. The six year completion rate is $67 \%$ in Australia (Edwards \& McMillan, 2015), 59\% in the United States (United States Department of Education, 2015) and ranges from 46\% to $80 \%$ in Europe (Quinn, 2013).

Of particular concern are the particularly poor outcomes for non-traditional students. For example, in Australia, nine year completion rates are $69 \%$ for LSES students compared to $78 \%$ for those from higher socioeconomic backgrounds and $47 \%$ for Indigenous students compared to $74 \%$ for non-Indigenous students (Edwards \& McMillan, 2015). European research also highlights that LSES status is the most significant factor associated with dropping out of higher education (Quinn, 2013). Non-traditional students also often belong to multiple equity groups (for instance are Indigenous and LSES) and are more likely to have other characteristics such as studying part time or lower academic entry scores. These factors compound to further negatively affect completions (Edwards \& McMillan, 2015). However, caution is required when implying that pre-existing factors such as SES or entry scores are the reason for the poorer success of the individuals and the group as a whole. For example as Kemp and Norton (2014) found, Australian Tertiary Admissions Rank (ATAR) scores are not a measure of academic potential and students with lower-ATAR can achieve success. While these student characteristics may be predictive factors, the relationship between them and student completions is not directly causal: that is, a student's SES status, ethnicity or entry score is not the cause of their success or failure.

In a similar vein, students give a range of reasons for withdrawing from their studies including quality, psychosocial, financial, practical, and academic (Coates, 2014). Of particular note, equity group students more often cite finance and family obligations as reasons, whereas non-equity group students' reasons centre more on choice and lifestyle (Edwards \& McMillan, 2015). However, as with demographic factors, we do not yet fully understand the processes by which these factors influence students' university experiences and lead to withdrawal for some students but not for similar others. If we are to understand these different outcomes, we need a better understanding of the mechanisms that 
explain the relationships between institutional and student characteristics, and student learning and success.

One known pathway to success is student engagement. In 1984, Astin was grappling with a similar issue: a large body of research demonstrated that there were associations between educational programmes and student achievement. But there was a missing link - a 'mediating mechanism' that would explain how institutional actions influenced student outcomes. Astin (1984) proposed student involvement as that missing link. This idea was the seed for a large body of research on what is now termed student engagement. However, while we now have considerable evidence that Astin was correct in his estimation of the role of student engagement, we still do not fully understand the complex ways that individual and institutional factors interact to influence that engagement. The remainder of this article addresses this issue by integrating ideas from transition theory and cultural studies to extend Kahu's (2013) earlier framework of student engagement, to provide a richer understanding about the complexity of students' experiences and to provide a useful framework to guide practice in the area of student success and retention.

\section{Student engagement theory}

Student engagement is key to student achievement and retention (Krause \& Coates, 2008) with notions of success and student engagement inextricably inter-twined. As Tinto (2014) says succinctly, 'engagement matters' (p. 20). But engagement is a complex and contested construct with multiple theories and a plethora of reviews (e.g. Trowler \& Trowler, 2010; Zepke \& Leach, 2010). Kahu's (2013) critical analysis of the literature identified three approaches to engagement: behavioural, emphasising student behaviours and teaching practices (stemming from Astin's early work); psychological, viewing engagement as an internal psycho-social process with behavioural, cognitive, and affective dimensions (for a review see Fredricks et al., 2004); and socio-cultural, emphasising the broader social context of engagement (e.g. Mann, 2001). Drawing these approaches together, Kahu (2013) proposes an integrative framework which emphasises engagement as a variable state that is influenced by a wide array of student and institutional factors, as well as by the sociopolitical context within which the students, teachers, and institutions are situated. The framework also acknowledges the outcomes of engagement: It is through being engaged with their study that students learn and thus not only acquire skills and knowledge, but also experience academic success and personal growth.

Bryson (2014), like Astin (1984), suggests that student engagement is a black box and draws on a metaphor of quantum mechanics to argue that the complexity of student engagement is such that we cannot measure or map all of its properties. Like Kahu (2013), he argues that institutional factors and structural factors in a student's background are related to student engagement, and engagement 
results from the complex interplay between factors. However both these contributions are limited in that neither has identified 'mediating mechanisms' underpinning that interplay - in order to improve student success, we need to better understand how the various factors interact and impact student engagement and therefore success. To address these limitations we turn to the body of literature looking at student transitions and use those ideas to further refine Kahu's (2013) conceptual framework.

\section{Transition theory}

Transition theory aimed to understand why higher education, particularly the first year, is challenging and why so many students therefore withdraw or fail in that year. It sought to provide practical responses to the identified challenges. In some ways it is the opposite of engagement theory which aims to explain why students succeed. Three broad theoretical explanations of the challenge are evident (e.g. Devlin, 2013; Gale \& Parker, 2014) and describe the 'gaps' between student and institution differently and so offer different solutions. First, early theorising argued the problem was insufficient skills. Often targeting 'at-risk' cohorts, this explanation assumed that, due to their demographic characteristics, these students will have poorer literacy, numeracy, and academic skills (Warren, 2002). The transition metaphor here depicts university staff as masters teaching student apprentices the skills necessary for the trade of higher education. Solutions were co-curricular and focused on filling the skills or knowledge gap through supplementary instruction or services (Wilson, 2009). However, this perspective is too narrowly conceptualised - the difficulties many students face extend beyond a lack of skills and in fact 'speak to a cultural inequity' (McKay \& Devlin, 2014, p. 958).

The second explanation, academic socialisation, argues students also need to be inducted into the cultural ways of the academy (Lea \& Street, 2006). Here the transition metaphor is a maze and students leave or fail because they don't know how to navigate. Despite increasingly diverse student populations, the overarching academic culture continues to assume traditional young, white, middleclass learners, thus making navigation more challenging for others (Read, Archer, \& Leathwood, 2003). Solutions were delivered within the curriculum so that all students had the opportunity to develop the skills and knowledge required to navigate the academy (Wilson, 2009). A key limitation of these first two approaches is that both view the student as in deficit - in skills and in cultural understandings (Smit, 2012). In addition, socialisation assumes that students should be moulded to fit the institution's existing culture.

The third explanation, founded in critical discourse analysis, argues that learning also involves identity and power (Lea \& Street, 2006) and draws on Bourdieu's (1997) ideas of habitus. Traditional students bring not just economic capital, but also embody cultural and social capital which is valued and represents power (Bourdieu, 1997). Educational institutions have maintained this order through 
institutional habitus, which favours the knowledge and experience of dominant groups (Thomas, 2002). For students whose embodied practices are not equally valued, institutional habitus can lead to alienation (Mann, 2001). Indigenous knowledges in particular have not been valued by the Western academy (Sefa Dei, 2000). Proponents of this view suggest we need to value what diverse students bring and create space 'not just for new kinds of students but also for the knowledges and ways of knowing that they embody' (Gale, 2011, p. 679).

Transition theory highlights that alignment, or misalignment, between student and institution is important for success. However, while transition theory usefully emphasises the importance of the first year and highlights the need for institutions to adapt to diverse students, attrition is not limited to the first year. For example $7.9 \%$ of Australian students dropped out after their first and before their second year, and a further 13.8\% dropped out in later years (Edwards \& McMillan, 2015). The experience of higher education is an ongoing 'transformation of being' (Barnett, 2007, p. 38). It requires an iterative navigation of difference between the student's individual habitus and the culture, knowledge, and practices of the academy - and not just during the transition to higher education. Each new learning experience has the potential to challenge students' ways of being and thinking, and to require students to bring their diverse identities and experiences to bear on new ideas. The transition metaphor therefore does not capture the lived experience of learning as a dynamic and constant reworking of the self (Quinn, 2010). Instead we need to 'reconceptualise transition in a way that reflects students' lived realities' (Gale \& Parker, 2014, p. 747). To do that, it is useful to view the experience of higher education through a cultural lens.

\section{A cultural lens - the educational interface}

The student deficit models of transition discussed draw on well-contested ideas of cultural deficit. In 1971, Valentine proposed the theory of biculturalism - cultures were not mutually exclusive, but rather people could be simultaneously socialised into two different ways of life. This idea extends beyond ethnicity and parallels contemporary understandings of identity as a continuous construction, with individuals moving between identities relating to their life roles (Hall, 2004). Dual socialisation is facilitated by the degree of overlap, of norms and values, between identities. So in education, students from high prestige schools with university educated parents have a greater overlap between their existing identities and that of higher education student. This overlap facilitates learning and encourages persistence (Kuh \& Love, 2000).

Devlin (2013) terms the lack of overlap for non-traditional students as 'sociocultural incongruity' and suggests a bridge, a joint venture between students, university, schools, and government, is a useful metaphor for conceptualising what is needed. However, the bridge metaphor, as with transition, suggests there is an end point. Nakata (2007), theorising indigenous student experiences, argues that a 'cultural interface' is a theoretically useful metaphor: 
The Cultural Interface... is a multi-layered and multi-dimensional space of dynamic relations constituted by the intersections of time, place, distance, different systems of thought, competing and contesting discourses within and between different knowledge traditions, and different systems of social, economic and political organisation. (p. 199)

Adapting this idea to describe the student experience and student engagement as an active process within an 'educational interface' has much to commend it. First, it is a positive metaphor, emphasising the importance of drawing on both ways of being, rather than focussing on any lack of alignment between cultures or positioning the student as in deficit. Second, the concept of an educational interface recognises the importance of student agency. As Nakata (2002) argues, this is 'the place where we are active agents in our own lives - where we make our decisions - our life world' (p. 285). In the educational interface, the student is not a passive actor required to sacrifice their existing ways of being; rather the goal is to negotiate the experience in between. Third, an interface is not a transition, a temporary state; it is the place where students continue to experience their world. The student is in a set of relationships within multiple educational settings and their sense of self is dynamic and fluctuating, varying according to the situation being experienced. The educational interface is a psychosocial space within which the individual student experiences their education. Integrating the concept of the educational interface with Kahu's (2013) framework of student engagement discussed earlier, shines a light into Astin's (1984) and Bryson's (2014) black box of student engagement and thus furthers our understanding of how different institutional and student characteristics interact to influence a student's engagement and success. Next we look more closely at the student experience within the interface.

\section{Experiencing the educational interface}

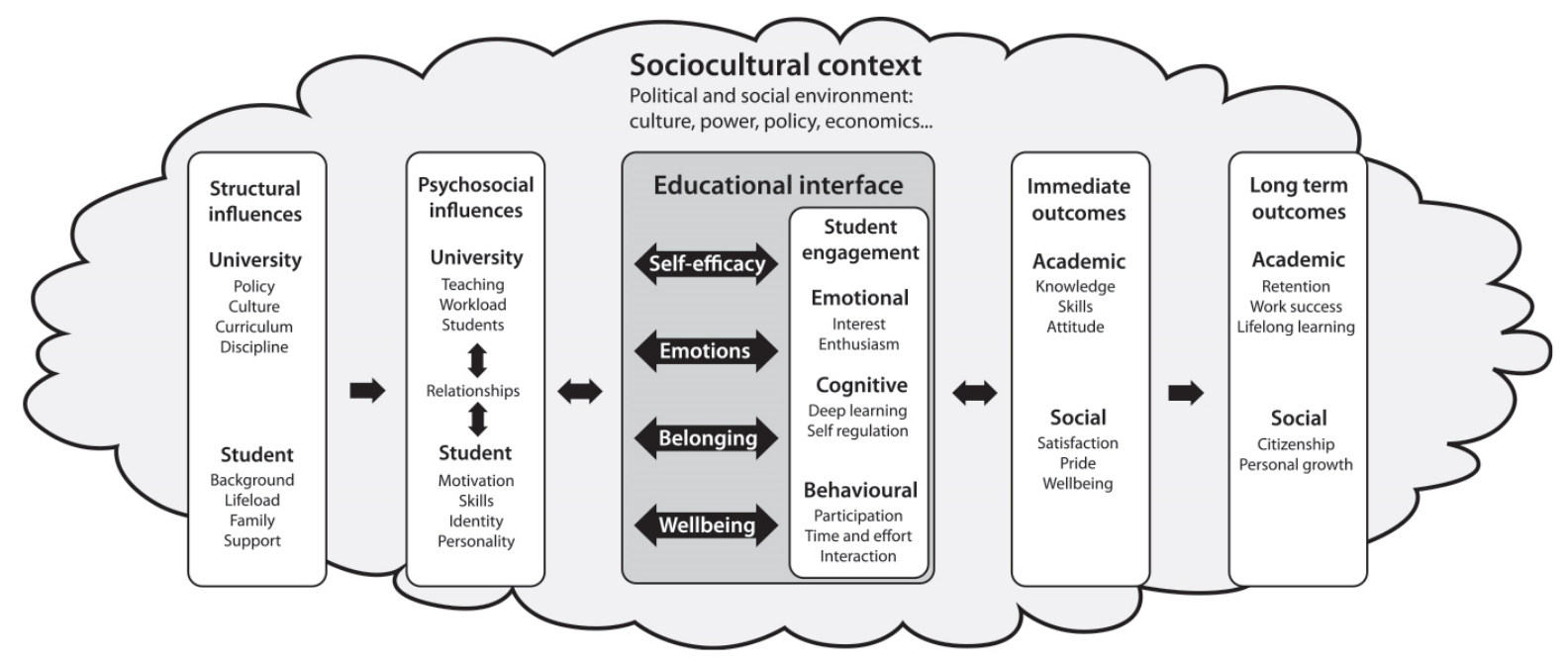

Figure 1. Refined conceptual framework of student engagement incorporating the educational interface 
Figure 1 presents a refined version of Kahu's (2013) conceptual framework of student engagement, depicting the central role of the educational interface. The interface is the place where students live and learn in higher education (Nakata, 2007); their experience is influenced by their background, skills, and motivations, but also by the institutional and wider context. The factors shown as student and institutional structural and psychosocial influences are not an exhaustive list, but rather indicative of the types of factors in each category. It is within this micro-context, when institutional and student factors align, that individual student engagement occurs. For instance, students engage emotionally when the curriculum is linked to their interests, life experiences, and future selves (Kahu, Stephens, Leach, \& Zepke, 2014), and cognitive engagement occurs when the student feels their skills align with the task at hand (Schunk \& Pajares, 2004).

The student experience comprises of more than just their engagement however, as shown in the revised framework. A search of the education literature for psychosocial constructs that strongly influence student outcomes and which result from the interaction between institutional and student characteristics reveals four constructs that illustrate important components of the student experience within the interface. These are: academic self-efficacy, the student's perception of their capabilities for the task at hand; emotions, resulting from the student's appraisal of their situation; belonging, the connection students feel to the institution, discipline, and people; and finally well-being, stemming in part from lifeload and stress. These four psychosocial constructs are best understood as mediating mechanisms: student and institutional factors may interact to directly influence student engagement, or engagement may be mediated via one of these four mechanisms. Next we briefly discuss how each construct manifests within the educational interface and impacts on engagement and success. We also highlight how each of these mediating mechanisms offer explanations for differences in outcomes for non-traditional students.

\section{Self-efficacy}

Self-efficacy is an individual's belief in their capacity to perform a given task, stemming from a cognitive appraisal of personal and environmental factors (Schunk \& Pajares, 2004). Self-efficacy is critical to behaviour: 'Unless people believe they can produce desired effects by their actions, they have little incentive to act' (Bandura, 1997, pp. 2-3). Academic self-efficacy influences student motivation and learning through its impact on persistence, goal setting, and the use of self-regulatory strategies (van Dinther, Dochy, \& Segers, 2011). High self-efficacy increases student engagement and success and, in return, engagement and success increase self-efficacy (Schunk \& Mullen, 2012).

Viewing self-efficacy as occurring within the educational interface acknowledges the complex array of intersecting institutional and student based factors, which influence a student's belief in their capabilities. It also highlights that self-efficacy may be one of the key mechanisms that could cause non-traditional students to be less engaged. Middle class students have higher academic self- 
confidence than working-class students who often express anxiety about their academic abilities (Crozier, Reay, \& Clayton, 2010); this then influences their self-efficacy. Schunk and Mullen (2012) also highlight the influence of family on self-efficacy - through cultural capital, encouragement, and role models - as well as the influence of wider sociocultural factors such as socioeconomic status. These are all factors underpinning the challenges facing non-traditional student groups and we concur with these authors that more research is needed on academic self-efficacy in non-traditional student groups.

\section{Emotions}

Appreciating students' emotional responses is essential to understanding and theorising student experiences (Linnenbrink, 2006). Emotions are situated and dynamic, and like self-efficacy, the result of a subjective appraisal of the situation (Fredrickson \& Cohn, 2008). Emotions therefore occur within the educational interface, and viewing them this way enables a clearer understanding of the complex roles emotions play. For example, Kahu et al. (2014) found that positive topic related emotions, interest and enthusiasm, stem from life integrated learning: the intersection between course material and the students' personal or work interests and experiences. Similarly, task based emotions, such as anxiety, depend on both the nature of the task and the student's skills, personality, and past experiences. Emotions within the interface also include social emotions, those related to people such as admiration and empathy (Pekrun \& Linnenbrink-Garcia, 2012).

The first year is a particularly emotional time for students. For non-traditional students, the gap between their existing identities and experiences and the expectations and requirements of the institution may result in more negative emotions. For example, lack of access to technology, concerns over money, and families who do not understand the pressures of tertiary study are all factors that can increase student anxiety and frustration and thus influence a student's engagement and success. While some anxiety can be a motivating force leading to greater behavioural engagement, chronic or extreme anxiety can have a negative impact and lead to disengagement and withdrawal (Kahu et al., 2014). Emotions are therefore another mechanism explaining differences between groups of students and another illustration of the effects of the complex interactions within the educational interface.

\section{Belonging}

The need for belonging, to have positive interpersonal attachments, is widely recognised as a fundamental human need (Baumeister \& Leary, 1995). In education settings, belonging is described as the students' connectedness to the institution, staff, and other students (Thomas, 2012), as well as the discipline being studied. Linking to Bourdieu's (1997) theory outlined earlier, belonging relates to the degree of fit an individual perceives between their individual habitus and that of the institution and is therefore usefully conceptualised as a component of the educational interface. Viewing belonging as the outcome of both institutional and student factors recognises that belonging can manifest 
differently for each student depending on their background, their personality, and other aspects of their experience. For example, mature-aged students have busy lives and may not seek a sense of belonging to the institution (Wyatt, 2011).

Belonging may influence retention directly. As discussed earlier, despite wider participation, academia still reflects traditional students. Others, who feel 'alienated by academic culture itself' (Read et al., 2003, p. 271), may choose to leave, regardless of how engaged they are with their study. Belonging can also influence success through its impact on engagement. For example, that sense of alienation may create anxiety, which then inhibits participation in classroom discussions hampering both behavioural and emotional engagement. Belonging can also have a positive impact on wellbeing.

\section{Well-being}

The final construct that we suggest is critical to understanding the educational interface is student well-being, and its opposite, stress. Attending university is stressful: Stallman (2010) found $84 \%$ of Australian students reported elevated distress, and 19\% reported high distress compared to 3\% of the general population. This stress can be caused by personal factors, institutional factors, or the intersection between the two. For example, conflict between study and other commitments affects half of first year Australian students (Baik, Naylor, \& Arkoudis, 2015). Stress can inhibit engagement with higher stress levels associated with lower academic motivation and enjoyment (Gavala \& Flett, 2005). Stress can also lead to withdrawal: $72 \%$ of first year Australian students who had seriously considered withdrawing cited emotional health as an important factor (Baik et al., 2015).

As with the other three constructs discussed, viewing well-being as an interaction within the educational interface, offers possible explanations for differences in the learning and persistence of non-traditional students. In particular, well-being is more likely to be compromised for students who belong to multiple equity groups (Edwards \& McMillan, 2015). For example, high levels of paid work, additional family responsibilities, or living far from campus (all characteristics of nontraditional students) are all potential causes of stress, which can influence student success by impeding student engagement.

As explained, recognising that student engagement and student learning occur within an educational interface at the intersection of institution and student is theoretically valuable. It illuminates some of the processes by which factors influence student success and helps us to understand the additional challenges faced by non-traditional students. We do not claim that the four psychosocial constructs depicted in the interface and discussed here are a definitive list of critical intersections between student and institution. They are however those that are most dominant in the current literature. In addition, while presented separately here for clarity, self-efficacy, emotions, belonging, and well-being are not discrete elements of experience. The student experience of the interface is complex and dynamic as Bryson (2014) reminds us, and there are many overlaps and 
interactions. One final benefit of viewing the student experience as occurring within an educational interface is the alignment with another key development in higher education: students as partners.

\section{Partnership}

It would be negligent not to acknowledge the work, mostly from the United Kingdom, calling for institutions to create supportive environments for diverse student bodies and to distribute the power more equitably by developing stronger relationships or partnerships between students and their institution. For instance, Student Participation in Quality Scotland (Sparqs) defines partnership as 'an equal relationship between two or more bodies working together towards a common purpose, respecting the different skills, knowledge, experience and capability that each party brings to the table' (Williamson, 2013, p. 8). Advocates argue that staff and students working together, whether in governance, research, or teaching spaces, facilitate student engagement students (Healey, Flint, \& Harrington, 2014). Our revised framework acknowledges the criticality of relationships, specifically including the construct as a key interaction within the 'Psychosocial Influences'. The students as partners literature, similar to research into other institutional practices such as relevant curriculum and early intervention programs, does not illuminate the mediating mechanisms or psychosocial processes that explain how these practices influence a student's engagement and outcomes. Our framework, and the educational interface in particular, provides that insight. For instance, including students as partners in governance structures may give the student a sense of belonging to the institution, which then leads to greater engagement with their study. Or including students as co-constructors of an assessment task may increase their self-efficacy, leading to increased engagement and success. Although our definition of student engagement is specifically focused on learning, the educational interface embraces the notion of partnership, of academy and student working together in a productive and cooperative relationship.

\section{Conclusions}

This article, by refining Kahu's (2013) framework of student engagement, addresses the limitations of the framework and increases its relevance and validity for understanding the student experience. It makes three important contributions to the literature on student engagement and success. First, it affirms that students' engagement is influenced by the interactions between student factors and institutional factors and by applying a cultural lens, represents the place that these interactions occur as the educational interface. This representation aligns with an increasing emphasis on higher education being a partnership between students and their institution. The interface also provides a new way of understanding what institutions need to do to activate students' academic engagement. The interface metaphor highlights students' constantly changing experiences - for each new group of students, with each new interaction, and on each new task. 
The second contribution the paper makes is to engagement theory. The presence of the educational interface serves to remind us that student or institutional factors only rarely influence student engagement separately and that the interplay between them is critical. For example, a lecture engages a student when the delivery style matches the student's personal preferences and/or the content aligns with their interests. In addition, the interface provides clarity about how the interplay can influence student engagement indirectly through the four mediating mechanisms within it. For example, feedback on a student's work increases the student's self-efficacy which then improves their engagement on future tasks. Or staff getting to know a student gives them a sense of belonging that then facilitates engagement in the classroom. The four key constructs within the interface do not guarantee engagement or success, instead they are mediating mechanisms that act to increase or decrease the likelihood of engagement and therefore success. The identification of these key mediating mechanisms provides focus for the design and implementation of learning and teaching, and student experience enhancement initiatives. As the framework makes clear, there are a multitude of interacting influences on engagement and often these will conflict, however we contend that activating the mechanisms in the interface at the intersection of institutional and student factors is one way of positively influencing student engagement.

The article's third contribution is to our understanding of the experiences of non-traditional students. Rather than viewing demographic characteristics as direct and negative influences on engagement and retention, the interface highlights specific mechanisms that may help explain differences in cohort outcomes. For non-traditional students, the limited overlap between their past experiences and the context of higher education, or the conditions of their life, may mean their experience with higher education is more challenging. As shown in the educational interface, these challenges may be due to reduced self-efficacy, a lack of belonging, negative emotions, or decreased well-being and increased stress. Each of these mechanisms can negatively impact on a student's engagement, inhibit their learning and then, in a downward spiral, lead to failure which further reduces self-efficacy and belonging, as well as increases anxiety and stress. The bottom of the spiral is withdrawal. The revised framework with the educational interface recognises the challenges faced by non-traditional students. While we value their identities and existing knowledges we cannot hide from the reality - that non-traditional students are less likely to complete higher education. However, there are many very successful non-traditional students and the educational interface illustrates how student engagement can be fostered for all students, and particularly for non-traditional students by adopting institutional practices that activate these key mediating mechanisms.

The responsibility for students' experiences in the educational interface lies with multiple stakeholders. The framework is embedded within the sociocultural context highlighting the critical role that government has to play; for example, policy that enables lower SES students with a greater lifeload to study part time and still receive support would increase well-being. The institutional context is also critical. It is through the curriculum that institutions mediate 'student-institution 
interactions to enhance the broader student experience' (Nelson, Kift, \& Clarke, 2012, p. 125). Here institutional flexibility is paramount - allowing students to study in ways that make their experience of the educational interface more positive (Gale \& Parker, 2014; Quinn, 2010). Finally, the student, as an active participant in their own learning, has the central role to play. Learning is a partnership and the experience of the interface is influenced as much by the student as it is by the institution. The ongoing task of both student and institution is to facilitate working in the interface in order to learn from each other and to draw on the strengths of both. 


\section{References}

Astin, A. W. (1984). Student involvement: A developmental theory for higher education. Journal of College Student Personnel, 25(4), 297-308. Retrieved from http://www.jcsdonline.org/

Baik, C., Naylor, R., \& Arkoudis, S. (2015). First year experience in Australian universities: Findings from two decades, 1994-2014. Melbourne, Australia: Melbourne Centre for the Study of Higher Education.

Bandura, A. (1997). Self-efficacy: The exercise of control. New York, NY: W H Freeman.

Barnett, R. (2007). A will to learn: Being a studen in an age of uncertainty. Maidenhead, United Kingdom: Society for Research into Higher Education \& Open University Press.

Baum, S., Ma, J., \& Payea, K. (2013). Education pays 2013: The benefits of higher education for individuals and society. Retrieved from https://trends.collegeboard.org/sites/default/files/education-pays-2013-full-report.pdf

Baumeister, R. F., \& Leary, M. R. (1995). The need to belong: Desire for interpersonal attachments as a fundamental human motivation. Psychological Bulletin, 117(3), 497-529. doi: 10.1037/0033-2909.117.3.497

Behrendt, L., Larkin, S., Griew, R., \& Kelly, P. (2012). Review of higher education access and outcomes for Aboriginal and Torres Strait Islander people: Final report. Canberra, Australia: Department of Industry, Innovation, Science, Research and Tertiary Education.

Bourdieu, P. (1997). The forms of capital. In A. H. Halsey, H. Laudner, P. Brown \& A. Stuart Wells (Eds.), Education: Culture, economy, and society (pp. 46-58). Oxford, United Kingdom: Oxford University Press.

Bradley, D., Noonan, P., Nugent, H., \& Scales, B. (2008). Review of Australian higher education final report. Canberra, Australia: Government Printing Service.

Bryson, C. (2014). Clarifying the concept of student engagement. In C. Bryson (Ed.), Understanding and developing student engagement (pp. 1-22). Abingdon, United Kingdom: Routledge.

Coates, H. (2014). Students' early departure intentions and the mitigating role of support. Australian Universities' Review, 56(2), 20-29.

Crozier, G., Reay, D., \& Clayton, J. (2010). Access, participation and diversity questions in relation to different forms of post-compulsory further and higher education. In M. David (Ed.), Improving learning by widening participation in higher education (pp. 62-94). London, United Kingdom: Routledge.

Department for Business Innovation and Skills. (2013). The benefits of higher education participation for individuals and society: Key findings and reports - 'The quadrants'. London, United Kingdom: BIS.

Devlin, M. (2013). Bridging socio-cultural incongruity: Conceptualising the success of students from low socio-economic status backgrounds in Australian higher education. Studies in Higher Education, 38(6), 939-949. doi: 10.1080/03075079.2011.613991

Edwards, D., \& McMillan, J. (2015). Completing university in a growing sector: Is equity an issue? Australian Council for Educational Research. Retrieved from http://research.acer.edu.au/higher_education/43/ 
Fredricks, J. A., Blumenfeld, P., \& Paris, A. (2004). School engagement: Potential of the concept, state of the evidence. Review of Educational Research, 74(1), 59-109. doi: $10.3102 / 00346543074001059$

Fredrickson, B. L., \& Cohn, M. A. (2008). Positive emotions. In M. Lewis, J. M. Haviland-Jones \& L. F. Barrett (Eds.), Handbook of emotions ( $3^{\text {rd }}$ ed., pp. 777-796). New York, NY: The Guilford Press.

Gale, T. (2011). Expansion and equity in Australian higher education: Three propositions for new relations. Discourse: Studies in the Cultural Politics of Education, 32(5), 669-685. doi: 10.1080/01596306.2011.620751

Gale, T., \& Parker, S. (2014). Navigating change: A typology of student transition in higher education. Studies in Higher Education, 39(5), 734-753. doi: 10.1080/03075079.2012.721351

Gavala, J. R., \& Flett, R. (2005). Influential factors moderating academic enjoyment/motivation and psychological well-being for Maori university students at Massey University. New Zealand Journal of Psychology, 34(1), 52-57.

Hall, D. E. (2004). Subjectivity. New York, NY: Routledge.

Healey, M., Flint, A., \& Harrington, K. (2014). Engagement through partnership: Students as partners in learning and teaching in higher education. York, United Kingdom: Higher Education Academy.

Kahu, E. R. (2013). Framing student engagement in higher education. Studies in Higher Education, 38(5), 758-773. doi: 10.1080/03075079.2011.598505

Kahu, E. R., Nelson, K., \& Picton, C. (2017). Student interest as a key driver of engagement for first year students. In Proceedings of STARS: Students Transitions Achievement Retention and Success Conference. Adelaide, Australia: STARS.

Kahu, E. R., Stephens, C. V., Leach, L., \& Zepke, N. (2014). Linking academic emotions and student engagement: Mature-aged distance students' transition to university. Journal of Further and Higher Education, 39(4), 481-497.doi: 10.1080/0309877X.2014.895305

Kemp, D., \& Norton, A. (2014). Report of the review of the demand driven funding system. Department of Education. Retrieved from https://education.gov.au/report-review-demanddriven-funding-system

Krause, K., \& Coates, H. (2008). Students' engagement in first-year university. Assessment \& Evaluation in Higher Education, 33(5), 493-505. doi: 10.1080/02602930701698892

Kuh, G. D., \& Love, P. G. (2000). A cultural perspective on student departure. In J. M. Braxton (Ed.), Reworking the student departure puzzle (pp. 196-212). Nashville, TN: Vanderbilt University Press.

Lea, M. R., \& Street, B. V. (2006). The "Academic Literacies" model: Theory and applications. Theory Into Practice, 45(4), 368-377. doi: 10.1207/s15430421 tip4504_11

Linnenbrink, E. A. (2006). Emotion research in education: Theoretical and methodological perspectives on the integration of affect, motivation, and cognition. Educational Psychology Review, 18(4), 307-314. doi: 10.1007/s10648-006-9028-x 
Mann, S. (2001). Alternative perspectives on the student experience: Alienation and engagement. Studies in Higher Education, 26(1), 7-19. doi: 10.1080/03075070020030689

McKay, J., \& Devlin, M. (2014). 'Uni has a different language ... to the real world': Demystifying academic culture and discourse for students from low socioeconomic backgrounds. Higher Education Research \& Development, 33(5), 949-961. doi: 10.1080/07294360.2014.890570

Nakata, M. (2002). Indigenous knowledge and the cultural interface: Underlying issues at the intersection of knowledge and information systems. IFLA Journal, 28(5-6), 281-291.

Nakata, M. (2007). Disciplining the savages: Savaging the disciplines. Canberra, Australia: Aboriginal Studies Press.

Nelson, K., Kift, S., \& Clarke, J. (2012). A transition pedagogy for student engagement and first-year learning, success and retention. In I. Solomonides, A. Reid \& P. Petocz (Eds.), Engaging with learning in higher education (pp. 117-144). Faringdon, United Kingdom: Libri.

Pekrun, R., \& Linnenbrink-Garcia, L. (2012). Academic emotions and student engagement. In S. L. Christenson, A. L. Reschly \& C. Wylie (Eds.), Handbook of research on student engagement (pp. 259-282). New York, NY: Springer.

Picton, C., Kahu, E. R., \& Nelson, K. (2017). Friendship supported learrning - the role of friendships in first-year students' university experiences. In Proceedings of STARS: Students Transitions Achievement Retention and Success Conference. Adelaide, Australia: STARS.

Quinn, J. (2010). Rethinking 'failed transitions' to higher education. In K. Ecclestone, G. Biesta \& M. Hughes (Eds.), Transitions and learning through the lifecourse (pp. 118-129). London, United Kingdom: Routledge.

Quinn, J. (2013). Drop-out and completion in higher education in Europe among students from under-represented groups. European Commission. Retrieved from http://www.nesetweb.eu/sites/default/files/HE\%20Drop\%20out\%20AR\%20Final.pdf

Read, B., Archer, L., \& Leathwood, C. (2003). Challenging cultures? Student conceptions of 'belonging' and 'isolation' at a post-1992 university. Studies in Higher Education, 28(3), 261277. doi: $10.1080 / 03075070309290$

Schunk, D. H., \& Mullen, C. A. (2012). Self-efficacy as an engaged learner. In S. L. Christenson, A. L. Reschly \& C. Wylie (Eds.), Handbook of research on student engagement (pp. 219-235). New York, NY: Springer.

Schunk, D. H., \& Pajares, F. (2004). Self-efficacy in education revisited: Empirical and applied evidence. In D. M. McInerney \& S. Van Etten (Eds.), Big theories revisited (pp. 115-138). Greenwich, CT: Information Age Publishing.

Sefa Dei, G. J. (2000). Rethinking the role of Indigenous knowledges in the academy. International Journal of Inclusive Education, 4(2), 111-132. doi: 10.1080/136031100284849

Smit, R. (2012). Towards a clearer understanding of student disadvantage in higher education: Problematising deficit thinking. Higher Education Research \& Development, 31(3), 369-380. doi: 10.1080/07294360.2011.634383

Stallman, H. M. (2010). Psychological distress in university students: A comparison with general population data. Australian Psychologist, 45(4), 249-257. doi:

10.1080/00050067.2010.482109 
Thomas, L. (2002). Student retention in higher education: The role of institutional habitus. Journal of Education Policy, 17(4), 423-442. doi: 10.1080/02680930210140257

Thomas, L. (2012). Building student engagement and belonging in higher education at a time of change: Final report from the What Works? student retention and success programme.

Tinto, V. (2014). Reflective practice: Tinto's South Africa lectures. Journal of Student Affairs in Africa, 2(2), 5-28. doi: 10.14426/jsaa.v2i2.66

Trow, M. (2006). Reflections on the transition from elite to mass to universal access: Forms and phases of higher education in modern societies since WWII. In J. Forest \& P. Altbach (Eds.), Interntational handbook of higher education (pp. 243-280). Dordrecht, The Netherlands: Springer.

Trowler, V., \& Trowler, P. (2010). Student engagement evidence summary. York, United Kingdom: The Higher Education Academy.

United States Department of Education. (2015). The condition of education 2015. U.S. Department of Education. Retrieved from https://nces.ed.gov/pubsearch/pubsinfo.asp?pubid=2015144

Valentine, C. (1971). Deficit difference, and bicultural models of Afro-American behavior. Harvard Educational Review, 41(2), 137-157.

van Dinther, M., Dochy, F., \& Segers, M. (2011). Factors affecting students' self-efficacy in higher education. Educational Research Review, 6(2), 95-108. doi: 10.1016/j.edurev.2010.10.003

Warren, D. (2002). Curriculum design in a context of widening participation in higher education. Arts and Humanities in Higher Education, 1(1), 85-99. doi: 10.1177/1474022202001001007

Williamson, M. (2013). Guidance on the development and implementation of a Student Partnership Agreement in universities. Edinburgy, United Kingdom: Spraqs.

Wilson, K. (2009). The impact of institutional, programmatic and personal interventions on an effective and sustainable first-year student experience. Paper presented at the 12th Pacific Rim First Year in Higher Educaiton Conference, Townsville, Australia. http://www.fyhe.com.au/past_papers/papers09/ppts/Keithia_Wilson_paper.pdf

Wyatt, L. G. (2011). Nontraditional student engagement: Increasing adult student success and retention. The Journal of Continuing Higher Education, 59(1), 10-20. doi: 10.1080/07377363.2011.544977

Zepke, N., \& Leach, L. (2010). Improving student engagement in post-compulsory education: A synthesis of research literature. Wellington, New Zealand: Teaching and Learning Research Initiative. 
Student engagement in the educational

interface: understanding the mechanisms of student success

Kahu, ER

2018

http://hdl.handle.net/10179/15151

22/04/2023 - Downloaded from MASSEY RESEARCH ONLINE 